\title{
Técnicas de antissepsia em procedimentos cirúrgicos ortopédicos: Um estudo comparativo*
}

\section{Antisepsis Techniques in Orthopedic Surgical Procedures: A Comparative Study}

\author{
Eugênio César Mendes ${ }^{1,20}$ Mauro de Castro Carvalho ${ }^{2}$ Rafael Baroni Carvalho ${ }^{2}$ Célio Alves Ferraz ${ }^{2}$ \\ Diba Maria S.T. Souza ${ }^{1}$ Taylor B. Schnaider ${ }^{1,2}$ \\ ${ }^{1}$ Universidade do Vale do Sapucaí, Pouso Alegre, Minas Gerais, MG, Brasil \\ ${ }^{2}$ Departamento de Ortopedia e Traumatologia, Hospital das Clínicas \\ Samuel Libânio, Pouso Alegre, Minas Gerais, MG, Brasil \\ Endereço para correspondência Eugênio César Mendes, MD, MSc, \\ Universidade do Vale do Sapucaí, Avenida Tuany Toledo 470, \\ Pouso Alegre, Minas Gerais, MG, 37550-000, Brasil \\ (e-mail: eugeniocmendes@hotmail.com).
} Rev Bras Ortop 2020;55(2):156-162.

\section{Resumo \\ Palavras-chave \\ - clorexidina \\ - infecção \\ - ortopedia \\ - salas cirúrgicas \\ - antissepsia \\ - procedimentos cirúrgicos}

\section{Abstract}

Objetivo Comparar as técnicas de antissepsia utilizando clorexidina degermante associada a álcool etílico e a clorexidina alcoólica versus clorexidina degermante associada a clorexidina alcoólica, em procedimentos cirúrgicos ortopédicos.

Métodos Trata-se de um estudo clínico, primário, randomizado, analítico e de centro único, constituído por 170 pacientes ortopédicos submetidos a abordagem cirúrgica, alocados em 2 grupos aleatórios, nos quais foram testados clorexidina degermante + clorexidina alcoólica (grupo CDCA) e clorexidina degermante + álcool etílico a 70\%+ clorexidina alcoólica (grupo CDACA). Foram realizadas culturas nos meios manitol e eosina azul de metileno (EAM) de amostras colhidas nos períodos de pré-degermação (0), pós-degermação (1) e após a incisão suturada (2).

Resultados Em relação ao crescimento bacteriano nos meios de cultura manitol e EAM entre os grupos, em cada período de estudo (0, 1 e 2), não ocorreu diferença estatística significativa nesta pesquisa. Na avaliação do tipo de crescimento bacteriano nos meios de cultura manitol e EAM, também não foi constatada significância estatística entre os grupos.

Conclusão Não ocorreu diferença entre as técnicas utilizadas na antissepsia para prevenção de infecção de sítio cirúrgico em procedimentos ortopédicos, mas, ao final do trabalho, foi possível a elaboração de um protocolo de medidas para realização de prevenção infecciosa nesses procedimentos.

Objective To compare antisepsis techniques using chlorhexidine-based soap associated with ethyl alcohol and alcohol-based chlorhexidine or chlorhexidine-based soap associated with alcohol-based chlorhexidine alone in surgical orthopedic procedures.

Trabalho Realizado no Hospital das Clínicas Samuel Libânio, Pouso Alegre, MG, Brasil.

recebido

16 de Agosto de 2018 aceito

08 de Janeiro de 2019
DOI https://doi.org/

$10.1055 / \mathrm{s}-0039-3400520$ ISSN 0102-3616.
Copyright $\odot 2020$ by Sociedade Brasileira License terms de Ortopedia e Traumatologia. Published by Thieme Revinter Publicações Ltda, Rio de Janeiro, Brazil 


\section{Keywords}

- chlorhexidine

- infection

- orthopedics

- operating rooms

- antisepsis

- surgical procedures
Methods This is a primary, randomized, analytical and single-center clinical trial consisting of 170 patients, who were divided into 2 groups. The combinations chlorhexidine-based soap + alcohol-based chlorhexidine (CSAC) and chlorhexidinebased soap $+70 \%$ ethyl alcohol + alcohol-based chlorhexidine (CSAAC) were tested in each group. The cultures were grown in mannitol and eosin methylene blue (EMB) after collection before skin preparation (time point 0 ), after skin preparation (time point 1 ) and at the end of the surgical procedure (time point 2 ).

Results There was no statistically significant difference regarding bacterial growth in mannitol and EMB between the groups at any time point. Moreover, there was no statistical difference between groups and time points regarding the type of bacterial growth in culture media.

Conclusion There was no difference between these antisepsis techniques for the prevention of surgical site infection in orthopedic procedures; in addition, a protocol containing measures to prevent infection in such procedures was developed.

\section{Introdução}

A infecção de sítio cirúrgico (ISC) é um dos assuntos mais pesquisados e mais frequentemente associados às complicações operatórias, vitimando até um terço dos pacientes submetidos a procedimentos cirúrgicos em países de baixa e média renda.

Dados dos Centers for Disease Control and Prevention estimam que quase 500 mil dessas manifestações ocorrem a cada ano, o que representa quase $1 / 4$ das infecções nosocomiais nos Estados Unidos anualmente. ${ }^{1}$

No Brasil, apesar de não haver dados sistematizados, as ISCs são apontadas em terceiro lugar entre as causas de infecção, sendo encontradas em aproximadamente 14\% a $16 \%$ dos pacientes hospitalizados. Além dos prejuízos físicos, psicológicos e financeiros aos pacientes acometidos, as ISCs podem prolongar a estadia do paciente em média de sete a onze dias, além de aumentar a chance de readmissão hospitalar, cirurgias adicionais, e, consequentemente, elevar exorbitantemente os gastos assistenciais com o tratamento, que podem chegar a US $\$ 1,6$ bilhão anuais. ${ }^{2,3}$

Revisões bibliográficas nos trazem dados históricos sobre a antissepsia, com procedimentos rudimentares, evidentemente longe de serem seguros e eficazes, como aqueles hoje conhecidos. ${ }^{4}$ Em uma revisão sistemática, Lee et $\mathrm{al}^{5}$ concluíram que compostos à base de clorexidina são mais eficazes na antissepsia do sítio cirúrgico do que o iodo, e resultam em economias significativas de custos.

Mears et al, ${ }^{6}$ Swenson et al, ${ }^{7}$ Saltzman et al, ${ }^{8}$ e Savage e Anderson ${ }^{1}$ conseguiram comprovar a maior eficácia da clorexidina com relação ao iodo. Reichel et $\mathrm{al}^{9}$ realizaram estudo comprovando a eficácia da associação álcool + clorexidina na antissepsia cutânea.

É consenso que a eficácia da preparação cutânea para realização do ato operatório tem impacto direto na ocorrência de ISC, e depende tanto do antisséptico utilizado quanto do método de aplicação. Contudo, não está claro qual antisséptico ou associação a ser usado, o tempo de ação, a metodologia utilizada na aplicação, ou o momento em que a antissepsia cutânea deve ser realizada. Por este motivo, o presente trabalho tem como objetivo comparar a eficácia da clorexidina degermante associada a álcool etílico e a clorexidina alcoólica versus clorexidina degermante associada a clorexidina alcoólica, e, assim, avaliar qual é a melhor forma de preparo da pele para procedimentos cirúrgicos ortopédicos em relação ao crescimento bacteriano e ao tempo cirúrgico.

\section{Materiais e Métodos}

Trata-se de um estudo clínico, primário, randomizado, prospectivo, analítico, simples-cego e de centro único, com o propósito de comparar as técnicas de antissepsia utilizando clorexidina degermante associada a álcool etílico e a clorexidina alcoólica, em procedimentos cirúrgicos ortopédicos. Os dados foram coletados no centro cirúrgico e no laboratório de pesquisa de um hospital de alta complexidade do Sistema Único de Saúde(SUS). Após aprovação pelo Comitê de ética em Pesquisa em 9 de maio de 2017 (parecer 2.054.709), o estudo foi realizado no período compreendido entre junho e novembro de 2017, conforme descrito a seguir.

Para o estudo, foram selecionados 190 pacientes segundo os critérios de elegibilidade, e chegou-se a uma amostra de 170 pacientes que seriam submetidos a procedimentos cirúrgicos ortopédicos.

Os critérios de inclusão no estudo foram: pacientes de ambos os gêneros; maiores de 18 anos; submetidos a todos os procedimentos cirúrgicos ortopédicos eletivos; que assinaram o termo de consentimento livre e esclarecido (TCLE). Os critérios de exclusão foram: pacientes submetidos a cirurgias de urgência/emergência; com histórico conhecido de alergia à clorexidina, ou que apresentaram algum tipo de reação cutânea ou sistêmica durante a aplicação do produto; com lesões de pele vigentes; oriundos do Centro de Tratamento Intensivo; que apresentaram fratura exposta no momento do atendimento inicial; e que utilizavam fixador externo para estabilização das fraturas. Também foram excluídos casos de óbito no pré-operatório e de perda de material. 
Pacientes que preencheram os critérios de elegibilidade foram separados, por meio de uma tabela de números aleatórios gerada pelo site http://www.randomization.com $\left(\mathrm{n}^{\circ}\right.$ 25432, em 8 de maio de 2017), em dois grupos: clorexidina degermante associada a álcool etílico a 70\% e a clorexidina alcoólica (CDACA), e clorexidina degermante associada a clorexidina alcoólica (CDCA). Foram seguidas as medidas de prevenção de infecção relacionada à assistência à saúde da Agência Nacional de Vigilância Sanitária (Anvisa), ${ }^{3}$ e os pacientes submetidos a cirurgias eletivas de grande porte, ou nos quais foram utilizados implantes ortopédicos durante o procedimento cirúrgico, foram devidamente preparados para o procedimento cirúrgico tomando, com 2 horas de antecedência, banho de corpo inteiro com a utilização de clorexidina $4 \%$. Já os pacientes submetidos a cirurgias eletivas de pequeno e médio porte utilizaram apenas sabonete neutro no banho de corpo inteiro. Exceções quanto ao banho de corpo inteiro foram feitas para os pacientes que utilizavam imobilizações gessadas devido ao fato de que, ao retirar a imobilização para o banho, isso causaria dor, desconforto e riscos, como perfuração da pele pela fratura.

Uma vez no centro cirúrgico, os pacientes receberam, de acordo com as descrições do protocolo de antibioticoprofilaxia, cefazolina $2 \mathrm{~g}$ endovenosa (EV) diluída em um frasco de $250 \mathrm{~mL}$ de cloreto de sódio a $0,9 \%$, iniciada 30 minutos antes do início do procedimento, e $1 \mathrm{~g} \mathrm{EV}$ de $8 \mathrm{~h}$ em $8 \mathrm{~h}$ por $24 \mathrm{~h}$ no pós-operatório. Também foi realizado exame de glicemia do paciente no pré-operatório, sendo colhido 30 minutos antes do início do procedimento, com nova coleta após o término da cirurgia. Pacientes que apresentavam pelos nos locais da incisão foram submetidos a procedimento de tricotomia com a utilização de tricotomizador da marca 3M (Maplewood, MN, EUA), sendo utilizadas lâminas descartáveis para cada paciente, conforme as medidas de prevenção de infecção relacionada à assistência à saúde da Anvisa. ${ }^{3}$

Após a realização do procedimento anestésico, foram iniciadas as coletas das amostras da microbiota da pele do paciente, com auxílio de $s w a b$ estéril em local previamente estipulado, no sítio cirúrgico, com extensão de $16 \mathrm{~cm}^{2}$, utilizando-se um campo de papel previamente recortado e esterilizado na Central de Esterilização, para isolar a região demarcada.

Os materiais coletados foram colocados em um tubo de ensaio com $1 \mathrm{~mL}$ de solução fosfatada tamponada, e encaminhados para o laboratório de pesquisa, onde foram semeados em uma placa com meio de cultura manitol e outra placa com meio de cultura eosina azul de metileno (EAM) para todos os momentos da coleta.

Todos os tubos de ensaio em que foram armazenadas as amostras colhidas, assim como as placas de cultura, foram numerados de acordo com cada paciente, seguindo sequencialmente os números de $1 \mathrm{a} 170$. Os tempos cirúrgicos de coleta foram identificados pelos números 0,1 e 2 , sendo que 0 número 0 corresponde aos materiais coletados na pré-degermação, o número 1 , aos materiais coletados no tempo pósdegermação com clorexidina degermante $4 \%$, seguido pela retirada do excesso com compressa seca ou embebida com álcool etílico a $70 \%$, e o número 2 , aos materiais coletados ao final do ato operatório (- Figura 1 ).

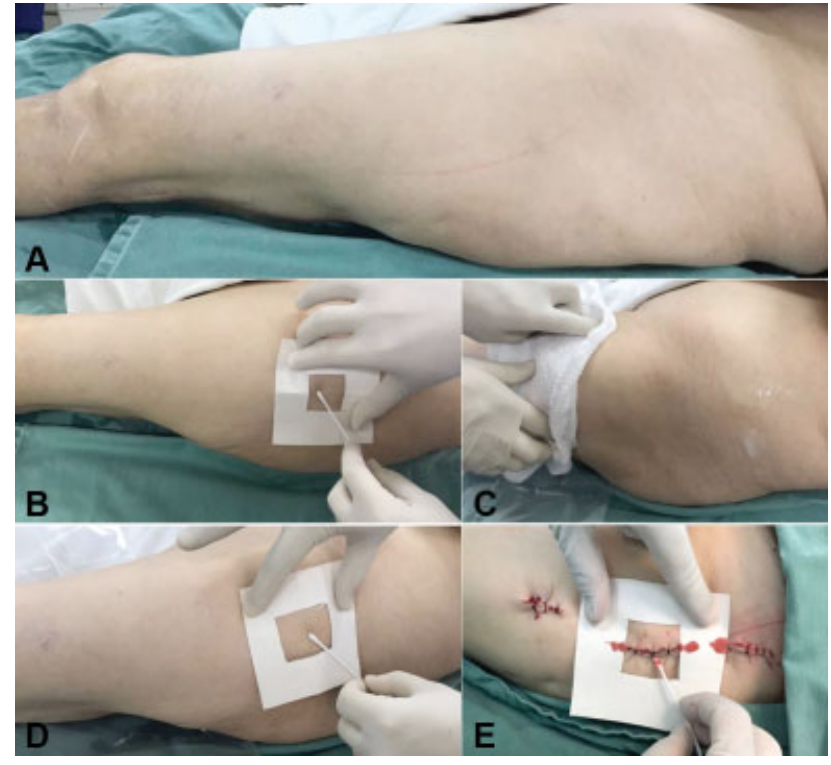

Fig. 1 Figuras ilustrando os tempos de coleta das amostras. (A) Paciente após ser anestesiado, com o membro a ser operado isolado com campos; (B) Coleta de amostra antes da degermação; (C) Realizada degermação com clorexidina degermante e retirado o excesso; (D) Coleta de amostra após a degermação; (E) Coleta de amostra ao final da cirurgia, após a sutura da ferida operatória, em ambiente ainda estéril.

Em ambos os grupos, foi coletada amostra da região a ser operada antes de proceder à degermação (tempo 0) com clorexidina degermante $4 \%$ por um prazo de 5 minutos, sendo utilizada uma compressa simples, estéril e embebida em álcool 70\% para retirar o excesso no grupo CDACA, e uma compressa simples, estéril e seca para retirar o excesso no grupo CDCA, efetuando movimento de proximal para distal no membro, apenas uma vez.

Após a degermação, foi coletada amostra estéril com a mesma técnica na área anteriormente estudada, seguida de antissepsia com clorexidina alcoólica e colocação de campos (tempo 1). Ao final do procedimento cirúrgico (incisão suturada), com o paciente ainda em ambiente estéril, foi colhida a amostra com a mesma técnica, no mesmo local demarcado (tempo 2). As amostras foram acondicionadas, separadamente, em tubos de ensaio com $1 \mathrm{~mL}$ de solução fosfatada tamponada e encaminhadas ao laboratório para análise.

Após 48 horas de o material ser semeado, os meios de cultura foram avaliados, e observou-se o crescimento ou não de microrganismos. Nos casos em que ocorreu, foi contado o número de colônias e identificadas bactérias Gram positivas (Staphylococcus aureus e não aureus) e Gram negativas. Foram comparados os meios de cultura pré-degermação, pós-degermação e ao final do procedimento tanto para o meio manitol quanto para o meio EAM, e avaliou-se se o número de colônias reduziu, se manteve igual, ou aumentou após a degermação. Quando houve crescimento nos meios de cultura identificados no tempo 2 (após incisão suturada), as placas foram lacradas com fita adesiva e encaminhadas ao laboratório de análises clínicas para realização de antibiograma. Dessa forma, todos os integrantes da casuística foram avaliados com relação à eficácia da antissepsia, assim como, quanto a quais microrganismos cresceram nas culturas realizadas. 
Os dados foram tabulados em planilhas do programa Microsoft Excel 2010 (Microsoft Corp., Redmond, WA, EUA) e submetidos a análise estatística. Para a análise do teste de Qui-quadrado foi utilizado o programa Statistical Package for the Social Sciences (SPSS, IBM Corp. Armonk, NY, EUA), versão 20.0.0, com nível de rejeição da hipótese de nulidade fixado em $5 \%$ ( $p \leq 0,05)$. Para as variáveis numéricas, utilizou-se estatística descritiva, com cálculos da média e mediana.

\section{Resultados}

O presente estudo compara a antissepsia realizada no Serviço de Ortopedia e Traumatologia utilizando clorexidina degermante associada a álcool etílico a 70\% e a clorexidina alcoólica versus clorexina degermante associada a clorexidina alcoólica. Para o presente estudo, 170 pacientes foram elegíveis para serem submetidos a abordagem cirúrgica, sendo separados em dois grupos de 85 pacientes cada: CDACA e CDCA. Durante a coleta, houve contaminação do material semeado em quatro placas sequenciais, em procedimento executado pelo mesmo residente, o que justificou a coincidência. Dessa forma, as placas foram eliminadas, e os pacientes foram excluídos do trabalho. Ao total, foram excluídos 4 pacientes, curiosamente sendo 2 de cada grupo, totalizando 166 pacientes divididos em 2 grupos de 83 pacientes cada.

Em relação ao crescimento bacteriano nos meios de cultura manitol e EAM entre os grupos, em cada tempo de estudo $(0,1$ e 2) foi evidenciada significância entre os grupos no tempo 0 (-Tabela 1), mas neste tempo não houve qualquer tipo de intervenção, ou seja, não houve relevância para o presente

Tabela 1 Crescimento bacteriano em meio de cultura Manitol nos grupos CDACA e CDCA em cada tempo do estudo: prédegermação (0), pós-degermação (1) e após incisão suturada (2)

\begin{tabular}{|l|l|l|l|l|l|l|l|}
\hline \multirow{2}{*}{ Manitol } & \multicolumn{2}{|l|}{ Grupo } & \multicolumn{2}{l|}{} \\
\cline { 3 - 8 } & \multicolumn{2}{|c|}{ CDACA } & \multicolumn{2}{l|}{ CDCA } & \multicolumn{2}{l|}{ Total } \\
\cline { 3 - 8 } & $\mathbf{n}$ & $\%$ & $\mathbf{n}$ & $\%$ & $\mathbf{n}$ & $\%$ \\
\hline $\begin{array}{l}\text { Tempo 0- } \\
\text { Pré- } \\
\text { degermação }\end{array}$ & $\begin{array}{l}\text { Não } \\
\text { cresceu }\end{array}$ & 6 & 7,3 & 16 & 19,3 & 22 & 13,3 \\
\cline { 2 - 8 } & Cresceu & 77 & 92,7 & 67 & 80,7 & 143 & 86,7 \\
\cline { 2 - 8 } & Total & 83 & 100,0 & 83 & 100,0 & 166 & 100,0 \\
\hline $\begin{array}{l}\text { Tempo 1- } \\
\text { Pós- } \\
\text { degermação }\end{array}$ & $\begin{array}{l}\text { Não } \\
\text { cresceu }\end{array}$ & 52 & 62,7 & 43 & 51,8 & 94 & 57,0 \\
\cline { 2 - 8 } & Cresceu & 31 & 37,3 & 40 & 48,2 & 71 & 43,0 \\
\cline { 2 - 8 } & Total & 83 & 100,0 & 83 & 100,0 & 166 & 100,0 \\
\hline $\begin{array}{l}\text { Tempo 2- } \\
\text { após incisão } \\
\text { suturada }\end{array}$ & $\begin{array}{l}\text { Não } \\
\text { cresceu }\end{array}$ & 52 & 62,7 & 51 & 61,4 & 103 & 62,0 \\
\cline { 2 - 8 } & Cresceu & 31 & 37,3 & 32 & 38,6 & 63 & 38,0 \\
\cline { 2 - 8 } & Total & 83 & 100,0 & 83 & 100,0 & 166 & 100,0 \\
\hline
\end{tabular}

Abreviaturas: CDACA, clorexidina degermante associada a álcool etílico a $70 \%$ e a clorexidina alcoólica; CDCA, clorexidina degermante associada a clorexidina alcoólica.

Nota: Ocorreu uma diferença estatística significativa $(p=0,024)$ entre os grupos com relação ao crescimento de bactéria em meio de cultura manitol no tempo 0 (pré-degermação): o grupo CDACA teve uma maior proporção de crescimento do que o grupo CDCA. Não foi observada diferença estatística significativa entre os grupos no tempo 1 $(p=0,138)$ e no tempo $2(p=0,873)$.
Tabela 2 Crescimento bacteriano em meio de cultura eosina azul de metileno nos grupos CDACA e CDCA em cada tempo do estudo: pré-degermação (0), pós-degermação (1) e após incisão suturada (2)

\begin{tabular}{|l|l|l|l|l|l|l|l|}
\hline \multirow{2}{*}{$\begin{array}{l}\text { Eosina azul } \\
\text { de metileno }\end{array}$} & \multicolumn{2}{|l}{ Grupo } \\
\cline { 3 - 9 } & \multicolumn{2}{|l|}{ CDACA } & \multicolumn{2}{l|}{ CDCA } & \multicolumn{2}{l|}{ Total } \\
\cline { 3 - 9 } & $\mathbf{n}$ & $\%$ & $\mathbf{N}$ & $\%$ & $\mathbf{n}$ & $\%$ \\
\hline \multirow{2}{*}{$\begin{array}{l}\text { Tempo 0- } \\
\text { pré- } \\
\text { degermação }\end{array}$} & $\begin{array}{l}\text { Não } \\
\text { cresceu }\end{array}$ & 67 & 80,7 & 62 & 74,7 & 128 & 77,6 \\
\cline { 2 - 9 } & Cresceu & 16 & 19,3 & 21 & 25,3 & 37 & 22,4 \\
\cline { 2 - 9 } & Total & 83 & 100,0 & 83 & 100,0 & 165 & 100,0 \\
\hline \multirow{2}{*}{$\begin{array}{l}\text { Tempo 1- } \\
\text { pós- } \\
\text { degermação }\end{array}$} & $\begin{array}{l}\text { Não } \\
\text { cresceu }\end{array}$ & 77 & 92,7 & 73 & 88,0 & 149 & 90,3 \\
\cline { 2 - 9 } & Cresceu & 6 & 7,3 & 10 & 12,0 & 16 & 9,7 \\
\cline { 2 - 9 } & Total & 83 & 100,0 & 83 & 100,0 & 165 & 100,0 \\
\hline \multirow{2}{*}{$\begin{array}{l}\text { Tempo 2- } \\
\text { após incisão } \\
\text { suturada }\end{array}$} & $\begin{array}{l}\text { Não } \\
\text { cresceu }\end{array}$ & 75 & 90,4 & 74 & 89,2 & 149 & 89,8 \\
\cline { 2 - 8 } & Cresceu & 8 & 9,6 & 9 & 10,8 & 17 & 10,2 \\
\cline { 2 - 8 } & Total & 83 & 100,0 & 83 & 100,0 & 166 & 100,0 \\
\hline
\end{tabular}

Abreviaturas: CDACA, clorexidina degermante associada a álcool etílico a $70 \%$ e a clorexidina alcoólica; CDCA, clorexidina degermante associada a clorexidina alcoólica.

Nota: Não houve diferença estatística significativa entre os grupos com relação ao crescimento de bactéria em meio de cultura eosina azul de metileno no tempo $0(p=0,373)$, no tempo $1(p=0,305)$, ou no tempo $2(p=0,798)$.

estudo. Nos demais tempos não houve significância estatística, ou seja, não houve diferença no resultado entre os diferentes métodos de aplicação ( - Tabela 2 ).

O tipo de crescimento bacteriano nos meios de cultura manitol e EAM e o tipo de bactéria que cresceu após incisão suturada não dependeram do método de aplicação (-Tabelas 3 e 4 ).

$\mathrm{Na}$ avaliação quantitativa relacionando os meios de cultura e os tempos de coleta, observou-se similaridade no número de colônias de bactérias formadas (expresso como n x10 UFC/mL) entre os dois métodos utilizados para antissepsia nesta

Tabela 3 Crescimento de cocos Gram positivos (CGP) e bacilos Gram negativos (BGN) em meio de cultura manitol nos grupos CDACA e CDCA

\begin{tabular}{|c|c|c|c|c|c|c|}
\hline \multirow[t]{3}{*}{ Bactérias } & \multicolumn{6}{|c|}{ Grupo } \\
\hline & \multicolumn{2}{|c|}{ CDACA } & \multicolumn{2}{|c|}{ CDCA } & \multicolumn{2}{|c|}{ Total } \\
\hline & $n$ & $\%$ & $\mathrm{~N}$ & $\%$ & $\mathrm{n}$ & $\%$ \\
\hline Não cresceu & 49 & 59,1 & 43 & 51,8 & 92 & 55,4 \\
\hline CGP & 29 & 35,8 & 31 & 37,4 & 60 & 36.1 \\
\hline BGN & 2 & 2.4 & 2 & 2,4 & 4 & 2.4 \\
\hline CGP e BGN & 3 & 3,6 & 7 & 8,4 & 10 & 6,1 \\
\hline Total & 83 & 100,0 & 83 & 100,0 & 166 & 100,0 \\
\hline
\end{tabular}

Abreviaturas: CDACA, clorexidina degermante associada a álcool etílico a 70\% e a clorexidina alcoólica; CDCA, clorexidina degermante associada a clorexidina alcoólica.

Nota: Não ocorreu diferença estatística significantiva $(p=0,536)$ entre os grupos com relação ao tipo de bactéria após incisão suturada. 
Tabela 4 Crescimento de cocos Gram positivos (CGP) e bacilos Gram negativos (BGN) em meio de cultura eosina azul de metileno nos grupos CDACA e CDCA

\begin{tabular}{|l|l|l|l|l|l|l|}
\hline \multirow{2}{*}{ Bactérias } & \multicolumn{4}{l|}{ Grupo } \\
\cline { 2 - 7 } & \multicolumn{2}{|l|}{ CDACA } & \multicolumn{2}{l|}{ CDCA } & \multicolumn{2}{l|}{ Total } \\
\cline { 2 - 7 } & $\mathrm{N}$ & $\%$ & $\mathrm{~N}$ & $\%$ & $\mathbf{n}$ & $\%$ \\
\hline Não cresceu & 51 & 61,4 & 52 & 62.6 & 103 & 62,0 \\
\hline CGP & 26 & 31,3 & 27 & 32.6 & 53 & 31.9 \\
\hline BGN & 0 & 0 & 0 & 0 & 0 & 0 \\
\hline CGP e BGN & 6 & 7,3 & 4 & 4,8 & 10 & 6,1 \\
\hline Total & $\mathbf{8 3}$ & $\mathbf{1 0 0 , 0}$ & $\mathbf{8 3}$ & $\mathbf{1 0 0 , 0}$ & 166 & 100,0 \\
\hline
\end{tabular}

Abreviaturas: CDACA, clorexidina degermante associada a álcool etílico a $70 \%$ e a clorexidina alcoólica; CDCA, clorexidina degermante associada a clorexidina alcoólica.

Nota: Não foi observada diferença estatística significativa $(p=0,783)$ entre os grupos com relação ao tipo de bactéria após incisão suturada.

pesquisa. Nas amostras obtidas, a média total de crescimento desses microorganismos foi de $27,3213 \times 10 \mathrm{UFC} / \mathrm{mL}$ e $27,5874 \times 10 \mathrm{UFC} / \mathrm{mL}$ nos grupos CDCA e CDACA, respectivamente (-Tabela 5).

Em relação ao crescimento bacteriano nos meios de cultura utilizados, nas amostras obtidas no tempo 2 (após a sutura da incisão), foi observado crescimento em 39\% dos casos. Essas amostras foram encaminhadas ao laboratório de análises clínicas, no qual se constatou a prevalência da

Tabela 5 Análise quantitativa das amostras nos meios de cultura nos diferentes tempos estudados

\begin{tabular}{|c|c|c|c|}
\hline Tempo & Placa & Grupo & $\begin{array}{l}\text { Média } \\
\text { (x } 10 \mathrm{UFC} / \mathrm{mL} \text { ) }\end{array}$ \\
\hline \multirow[t]{9}{*}{ Pré-degermação } & \multirow[t]{3}{*}{ EAM } & CDCA & 17,0843 \\
\hline & & CDACA & 12,1707 \\
\hline & & Total & 14,6424 \\
\hline & \multirow[t]{3}{*}{ Manitol } & CDCA & 116,7590 \\
\hline & & CDACA & 133,6951 \\
\hline & & Total & 125,1758 \\
\hline & \multirow[t]{3}{*}{ Total } & CDCA & 66,9217 \\
\hline & & CDACA & 72,9329 \\
\hline & & Total & 69,9091 \\
\hline \multirow[t]{9}{*}{ Pós-degermação } & \multirow[t]{3}{*}{ EAM } & CDCA & 4,9518 \\
\hline & & CDACA & 0,2317 \\
\hline & & Total & 2,6061 \\
\hline & \multirow[t]{3}{*}{ Manitol } & CDCA & 21,5542 \\
\hline & & CDACA & 4,1707 \\
\hline & & Total & 12,9152 \\
\hline & \multirow[t]{3}{*}{ Total } & CDCA & 13,2530 \\
\hline & & CDACA & 2,2012 \\
\hline & & Total & 7,7606 \\
\hline
\end{tabular}

Tabela 5 (Continued)

\begin{tabular}{|c|c|c|c|}
\hline Tempo & Placa & Grupo & $\begin{array}{l}\text { Média } \\
\text { (x } 10 \text { UFC/mL) }\end{array}$ \\
\hline \multirow{9}{*}{$\begin{array}{l}\text { Após incisão } \\
\text { suturada }\end{array}$} & \multirow[t]{3}{*}{ EAM } & CDCA & 0,3976 \\
\hline & & CDACA & 0,2439 \\
\hline & & Total & 0,3212 \\
\hline & \multirow[t]{3}{*}{ Manitol } & CDCA & 3,1807 \\
\hline & & CDACA & 15,0122 \\
\hline & & Total & 9,0606 \\
\hline & \multirow[t]{3}{*}{ Total } & CDCA & 1,7892 \\
\hline & & CDACA & 7,6280 \\
\hline & & Total & 4,6909 \\
\hline \multirow[t]{9}{*}{ Total } & \multirow[t]{3}{*}{ EAM } & CDCA & 4,4779 \\
\hline & & CDACA & 4,2154 \\
\hline & & Total & 5,8566 \\
\hline & \multirow[t]{3}{*}{ Manitol } & CDCA & 47,1647 \\
\hline & & CDACA & 50,9593 \\
\hline & & Total & 49,0505 \\
\hline & \multirow[t]{3}{*}{ Total } & CDCA & 27,3213 \\
\hline & & CDACA & 27,5874 \\
\hline & & Total & 27,4353 \\
\hline
\end{tabular}

Abreviaturas: CDACA, clorexidina degermante associada a álcool etílico a $70 \%$ e a clorexidina alcoólica; CDCA, clorexidina degermante associada a clorexidina alcoólica; EAM, eosina azul de metileno; UFC, unidade de formação de colônias.

Tabela 6 Análise microbiológica das amostras obtidas no tempo 2 (após incisão suturada)

\begin{tabular}{|l|l|}
\hline Bactéria & Frequência (\%) \\
\hline Staphylococcus epidermidis & 58,33 \\
\hline Staphylococcus aureus & 13,88 \\
\hline Acinetobacter iwoffii & 11,14 \\
\hline Staphylococcus saprophyticus & 4,16 \\
\hline Staphylococcus warneri & 4,16 \\
\hline Staphylococcus hominis & 2,77 \\
\hline Staphylococcus auricularis & 1,39 \\
\hline Staphylococcus capitis-capitis & 1,39 \\
\hline Staphylococcus haemolyticus & 1,39 \\
\hline Staphylococcus capitis-ureolyticus & 1,39 \\
\hline
\end{tabular}

bactéria Staphylococcus epidermidis (58,33\%), seguida da $S$. aureus (13,88\%) (-Tabela 6).

\section{Discussão}

Widerström ${ }^{10}$ avaliou a importância clínica dos estafilococos coagulase-negativos, particularmente o S. epidermidis, como uma importante causa de infecções associadas aos cuidados de saúde. Sua patogenicidade é favorecida pelo nicho natural na 
Tabela 7 Resultados encontrados pelos dados da CCIH em relação às cirurgias ortopédicas e à incidência de ISC no período de 2017

\begin{tabular}{|l|l|l|l|l|l|l|l|l|l|l|l|l|l|}
\hline Mês & Jan & Fev & Mar & Abr & Mai & Jun & Jul & Ago & Set & Out & Nov & Dez & Total \\
\hline Número de cirurgias & 115 & 101 & 135 & 139 & 131 & 146 & 152 & 129 & 130 & 124 & 123 & 136 & 1.561 \\
\hline ISC & 7 & 4 & 4 & 3 & 7 & 3 & 2 & 1 & 4 & 1 & 2 & 2 & 40 \\
\hline$\%$ & 6,1 & 4,0 & 2,96 & 2,16 & 5,34 & 2,05 & 1,32 & 0,78 & 3,08 & 0,81 & 1,63 & 1,47 & 2,64 \\
\hline
\end{tabular}

Abreviaturas: Central de Controle de Infecção Hospitalar (CCIH); ISC, infecção em sítio cirúrgico.

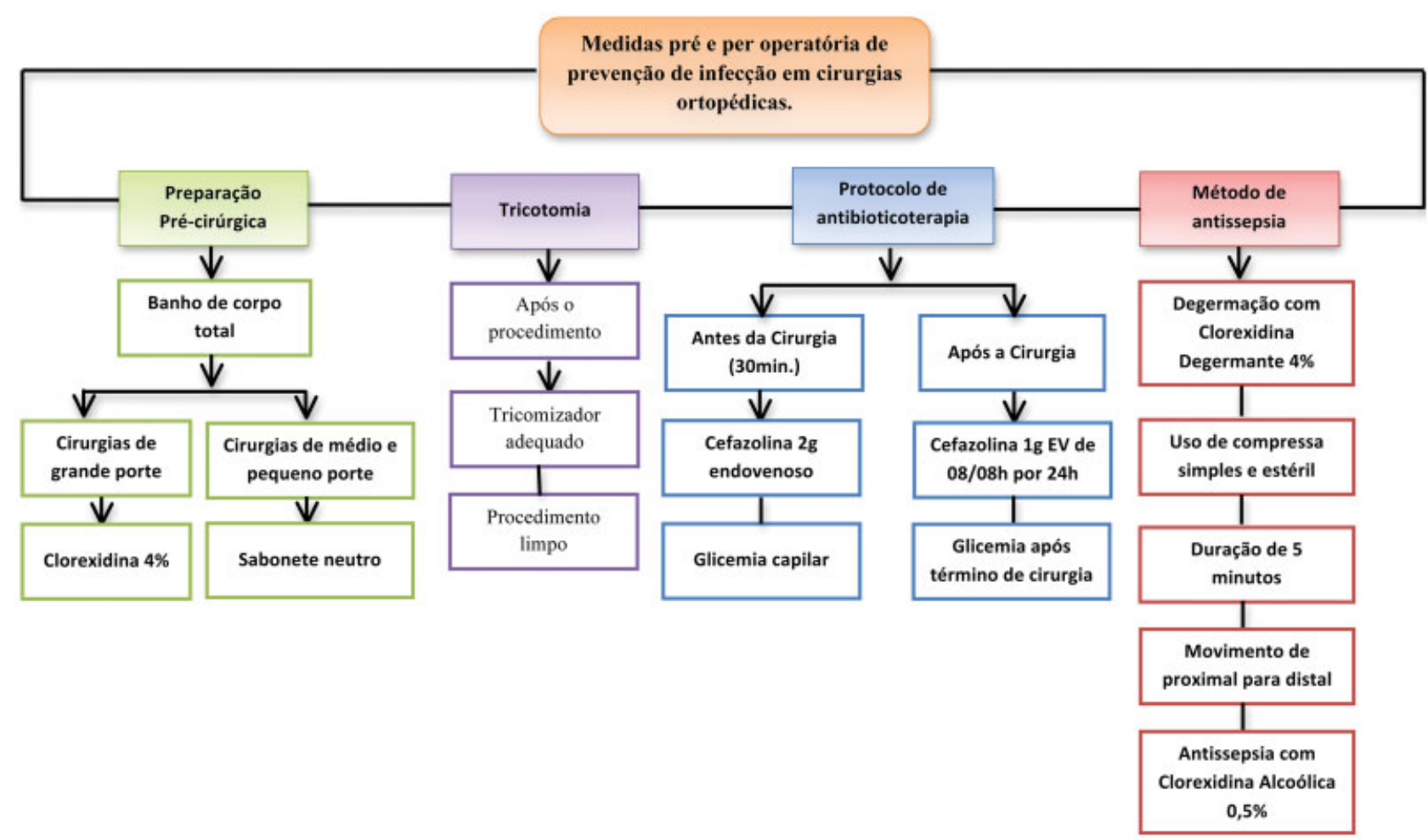

Fig. 2 Medidas pré- e peroperatórias de prevenção de infecção em cirurgias ortopédicas.

pele humana, resultando, assim, em ponto contaminação oportuno, o que reforça a importância do correto preparo cutâneo.

A melhor associação de antissépticos e a maneira e o tempo de aplicação ainda permanecem sem um consenso na literatura. Martínez et al $^{11}$ realizaram o primeiro ensaio clínico para comparar o álcool isopropílico e a clorexidina em álcool isopropílico para antissepsia da pele, com a finalidade de evitar a contaminação da hemocultura. Os autores evidenciaram que as taxas de contaminação do sangue não foram diferentes quando o álcool isopropílico e a clorexidina foram comparados. ${ }^{11}$

Uma revisão ${ }^{12}$ das diretrizes americanas, inglesas e francesas constatou que não existe um consenso quanto à forma de aplicação dos antissépticos. Enquanto as diretrizes americana e inglesa não são claras quanto à limpeza da pele antes de aplicar o antisséptico (uma abordagem que pode melhorar a sua eficácia, reduzindo a quantidade de bactérias e material proteico sobre a pele), as diretrizes francesas recomendam limpar a pele com um detergente antes da desinfecção. ${ }^{12}$

Com os resultados obtidos no presente trabalho, não foi observada qual é a melhor associação para antissepsia nos pacientes ortopédicos, mas, com base em dados fornecidos pela Central de Controle de Infecção Hospitalar (CCIH) da nossa instituição ( - Tabela 7), ao final do estudo, foi observada uma queda das taxas de ISC nos pacientes ortopédicos, o que corrobora o princípio de que a elaboração e adoção de um protocolo ( - Figura 2) é capaz de reduzir de forma significativa as taxas de ISC.

\section{Conclusão}

Não ocorreu diferença estatística entre a clorexidina degermante associada a álcool etílico e a clorexidina alcoólica e a clorexidina degermante associada a clorexidina alcoólica na antissepsia para a prevenção de ISC em cirurgias ortopédicas. Porém, observou-se que a adoção de um protocolo de medidas pré-, per- e pós-operatórias é eficaz na diminuição das taxas de ISC.

É possível que novos trabalhos com uma casuística maior possam apresentar maiores detalhes quanto à melhor forma de aplicação dos antissépticos. Sendo assim, continua a discussão de qual é o melhor antisséptico e a melhor forma de aplicá-lo.

Conflito de Interesses

Os autores declaram não haver conflito de interesses. 


\section{Referências}

1 Savage JW, Anderson PA. An update on modifiable factors to reduce the risk of surgical site infections. Spine J 2013;13(09):1017-1029

2 Brasil. Ministério da Saúde. Sítio cirúrgico: critérios nacionais de Infecções relacionadas à assistência à saúde [acesso em 2017 abr. 10]. Brasília: Agência Nacional de Vigilância Sanitária; 2009. Disponível em: http://www.anvisa.gov.br/servicosaude/manuais/criterios_nacionais_ISC.pdf

3 Brasil. Ministério da Saúde. Medidas de prevenção de infecção relacionada à assistência à saúde [acesso em 2017 abr. 10]. Brasília: Agência Nacional de Vigilância Sanitária; 2017. Disponível em: http://portal.anvisa.gov.br/documents/33852/3507912/Caderno+ 4+-+Medidas+de+Preven\%C3\%A7\%C3\%A3o+de+Infec\%C3\%A7\% C3\%A3o+Relacionada $+\%$ C3\%A0+Assist\%C3\%AAncia+\%C3\%A0+Sa\% C3\%BAde/a3f23dfb-2c54-4e64-881c-fccf9220c373

4 Saldmann F. On s'en lave les mains. Tout connaître des nouvelles règles de l'hygiène. Paris: Flammarion; 2007

5 Lee I, Agarwal RK, Lee BY, Fishman NO, Umscheid CA. Systematic review and cost analysis comparing use of chlorhexidine with use of iodine for preoperative skin antisepsis to prevent surgical site infection. Infect Control Hosp Epidemiol 2010;31(12):1219-1229

6 Mears SC, Dinah AF, Knight TA, Frassica FJ, Belkoff SM. Visibility of surgical site marking after preoperative skin preparation. Eplasty 2008;8:e35
7 Swenson BR, Hedrick TL, Metzger R, Bonatti H, Pruett TL, Sawyer RG. Effects of preoperative skin preparation on postoperative wound infection rates: a prospective study of 3 skin preparation protocols. Infect Control Hosp Epidemiol 2009;30 (10):964-971

8 Saltzman MD, Nuber GW, Gryzlo SM, Marecek GS, Koh JL. Efficacy of surgical preparation solutions in shoulder surgery. J Bone Joint Surg Am 2009;91(08):1949-1953

9 Reichel M, Heisig P, Kohlmann T, Kampf G. Alcohols for skin antisepsis at clinically relevant skin sites. Antimicrob Agents Chemother 2009;53(11):4778-4782

10 Widerström M. Significance of Staphylococcus epidermidis in Health Care-Associated Infections, from Contaminant to Clinically Relevant Pathogen: This Is a Wake-Up Call!. J Clin Microbiol 2016;54(07):1679-1681

11 Martínez J, Macías JH, Arreguín V, Álvarez JA, Macías AE, Mosqueda-Gómez JL. Isopropyl alcohol is as efficient as chlorhexidine to prevent contamination of blood cultures. Am J Infect Control 2017;45(04):350-353

12 Mimoz O, Chopra V, Timsit JF. What's new in catheter-related infection: skin cleansing and skin antisepsis. Intensive Care Med 2016;42(11):1784-1786 